\title{
TRẦM CẢM CỦA SINH VIÊN Y KHOA: GÓC NHÌN CỦA SINH VIÊN Y KHOA QUA MỌT NGHIÊN CÚ'U ĐỊNH TÍNH
}

\author{
Lê Hồng Hoài Linh, Bùi Hồng Cẩm, Trương Trọng Hoàng và Tô Hoàng Linh \\ Trường Đại học Y khoa Phạm Ngọc Thạch
}

Trầm cảm đang dần trở thành vấn đề y tế công cộng cần được quan tâm khi tỷ lệ người mắc trầm cảm ở mọi độ tuổi đang tăng lên một cách nhanh chóng. Nghiên cứu này nhằm mục tiêu mô tả cảm nhận của sinh viên y đa khoa về tình trạng trầm cảm và các yếu tố liên quan đến trầm cảm ở sinh viên y đa khoa chính quy Trường Đại học Y khoa Phạm Ngọc Thạch năm 2019, với sụ̣ tham gia của 4 sinh viên. Kết quả nghiên cứu cho thấy rằng sinh viên y khoa nhận thức được tỷ lệ trầm cảm của sinh viên y khoa đang ngày một tăng, các yếu tố liên quan bao gồm: Tuổi, giới tính, thói quen ăn uống, thói quen ngủ, mối quan hệ với gia đình, mối quan hệ với bạn bè, gặp trở ngại khi tham gia các hoạt động xã hội, học lực, áp lực từ việc học, chương trình học.

Từ khóa: Trầm cảm, các yếu tố liên quan, sinh viên y khoa, nghiên cứu định tính

\section{I. ĐẠT VẤN ĐỀ}

Theo Tổ chức $\mathrm{Y}$ tế Thế giới (WHO), trầm cảm là một rối loạn tâm thần phổ biến, đặc trưng bởi nỗi buồn dai dẳng, mất hứng thú với các hoạt động thường thích, kèm theo việc không thể thực hiện các hoạt động thường ngày trong ít nhất 2 tuần. ${ }^{1}$

Trầm cảm đã và đang trở thành gánh nặng lớn đối với sức khỏe cộng đồng ở hầu hết các quốc gia trên toàn thế giới. ${ }^{2}$ Theo ước tính mới nhất của WHO, hiện có hơn 300 triệu người mọi lứa tuổi đang mắc trầm cảm, tăng hơn 18\% trong giai đoạn 2005 - 2015. ${ }^{3}$

Số lượng sinh viên đại học gặp phải các vấn đề về sức khỏe tâm thần đã gia tăng ở nhiều nước trên toàn thế giới, trong đó chủ yếu là các chứng trầm cảm, lo âu. ${ }^{4}$ Theo nghiên cứu của Trần Quỳnh Anh và các cộng sự, thực hiện trên 2.099 sinh viên ở 8 Trường Đại học $Y$ khoa lớn trên cả nước, cho thấy có $43,2 \%$ trong 2.099 sinh viên có dấu hiệu trầm cảm. ${ }^{5}$

Một nghiên cứu định tính về trầm cảm của

Tác giả liên hệ: Tô Hoàng Linh

Trường Đại học Y khoa Phạm Ngọc Thạch

Email: dr.linhto1204@gmail.com

Ngày nhận: 16/07/2021

Ngày được chấp nhận: 16/08/2021 sinh viên y khoa tại Thái Lan năm 2020 cho thấy rằng, các nhóm yếu tố liên quan đến trầm cảm của sinh viên bao gồm: các yếu tố di truyền, hành vi lối sống, mối quan hệ cộng đồng xã hội, thành tích học tập, động lực học tập, môi trường học tập và chương trình giáo dục y tế. ${ }^{6}$

Đã có nhiều nghiên cứu định lượng được tiến hành để xác định tỉ lệ sinh viên y khoa mắc trầm cảm và các yếu tố liên quan đến tình trạng trầm cảm của sinh viên y khoa tại Việt Nam. Tuy nhiên, theo chúng tôi tìm hiểu đến nay vẫn chưa có một nghiên cứu nào được tiến hành để ghi nhận thực trạng trên dưới góc nhìn của chính người trong cuộc - sinh viên y khoa. Vì thế chúng tôi thực hiện nghiên cứu này với mục tiêu: Mô tả cảm nhận của sinh viên y đa khoa về tình trạng trầm cảm và các yếu tố liên quan đến trầm cảm ở sinh viên y đa khoa chính quy Trường Đại học Y khoa Phạm Ngọc Thạch năm 2019.

\section{II. ĐỐl TƯƠ'NG VÀ PHƯO'NG PHÁP}

\section{1. Đối tượng}

Đối tượng nghiên cứu: Sinh viên y đa khoa chính quy đang theo học tại Trường Đại học $Y$ khoa Phạm Ngọc Thạch. 
Tiêu chuẩn chọn vào: Sinh viên có tổng số điểm thang đánh giá CES - D20 từ 40 điểm trở lên và đồng ý tham gia phỏng vấn.

Tiêu chuẩn loại ra: Sinh viên không hợp tác trong quá trình thực hiện phỏng vấn.

\section{Phương pháp}

Thò̀i gian nghiên cứu: Từ tháng 05/2019 đến tháng 06/2019.

Địa điểm nghiên cứu: Trường Đại học $Y$ khoa Phạm Ngọc Thạch.

Thiết kế nghiên cứu: Nghiên cứu định tính với cách tiếp cận tường thuật mô tả.

Cỡ mẫu: Chúng tôi dự định phỏng vấn sau 6 sinh viên đại diện cho mỗi khối (Y1, Y2, Y3, Y4, Y5, Y6). Tuy nhiên, trên thực tế chúng tôi đã phỏng vấn sâu 4 sinh viên vì số lượng thông tin thu thập đã đạt được độ bão hòa.

Kỹ thuật chọn mẫu: Chọn mẫu ngẫu nhiên có mục đích với những ca ngoại biên. Thang đánh giá CES - D20 theo đánh giá chuẩn của quốc tế thì điểm 16 là mốc (cut - off point) để phân loại giữa có và không có nguy cơ trầm cảm. Chúng tôi đã chọn ngẫu nhiên những sinh viên từ danh sách 20 sinh viên y đa khoa chính quy đang theo học tại Trường Đại học $Y$ khoa Phạm Ngọc Thạch có tổng số điểm thang đánh giá CES - D20 từ 40 điểm trở lên (trầm cảm nặng) thu được từ bộ số liệu định lượng của nghiên cứu trước (Phần định lượng của nghiên cứu này đã được công bố tại Hội nghị Khoa học Công nghệ Tuổi trẻ lần thứ XII tại trường Đại học Y khoa Phạm Ngọc Thạch năm 2019).

Biến số nghiên cúru: Xây dựng chuỗi đề mục theo mô hình Dahlgren và Whitehead ${ }^{7}$ với các biến số: Vấn đề sức khỏe: Tình trạng trầm cảm. Các yếu tố sinh học: Tuổi, giới tính. Hành vi, lối sống: Thói quen ăn uống, thói quen ngủ. Mạng lưới cộng đồng xã hội: Mối quan hệ với gia đình, mối quan hệ với bạn bè, gặp trở ngại khi tham gia các hoạt động xã hội. Điều kiện sống và làm việc: Học lực, áp lực từ việc học, chương trình học, thi rớt môn hoặc nợ môn, nơi ở. Điều kiện kinh tế - xã hội, văn hóa, môi trường: Mức học phí, chi phí sách vở, dụng cụ học tập, dân tộc, tôn giáo.

Công cự thu thập số liệu: Bộ câu hỏi phỏng vấn sâu bán cấu trúc gồm 8 câu hỏi về suy nghĩ, quan điểm của người được phỏng vấn về tình trạng trầm cảm và các yếu tố liên quan đến trầm cảm ở sinh viên với các câu hỏi theo đề mục được xây dựng trước đó. Sổ, bút, máy ghi âm để ghi chép lại các nội dung khi phỏng vấn sâu.

Phương pháp thu thập số liệu: Phỏng vấn sâu: những bạn sinh viên được lựa chọn đã được giải thích rõ về tính ẩn danh và bảo mật của nghiên cứu. Đồng thời khẳng định rằng không có câu trả lời nào là đúng hoặc sai, đây chỉ là quan điểm cá nhân. Chọn địa điểm phỏng vấn phù hợp, thoải mái, ghi âm cuộc phỏng vấn khi đã được sự cho phép của các bạn sinh viên. Mỗi buổi chỉ phỏng vấn 1 sinh viên. Các nghiên cứu viên đã được tập huấn phỏng vấn sâu với các chuyên gia trong lĩnh vực nghiên cứu định tính. Khi tiến hành phỏng vấn sâu, một người trong nhóm nghiên cứu tiến hành phỏng vấn dựa theo bộ câu hỏi phỏng vấn sâu bán cấu trúc, một người khác làm thư ký ghi chép nội dung cuộc phỏng vấn và hỏi bổ sung câu hỏi khi cần thiết. Buổi phỏng vấn kéo dài khoảng từ 15 đến 30 phút.

\section{Xử lý số liệu}

Các nghiên cứu viên đã cùng rã băng phỏng vấn, sau đó đối chứng bản rã băng với nhau xem nội dung rã băng đã trùng khớp chưa, cùng nghe lại đoạn băng khi chưa trùng khớp và xem lại bảng ghi chép trên sổ để có thông tin chính xác nhất. Các thông tin thu thập được đã được tổng hợp và lưu dưới định dạng Word 2016. Xây dựng bảng mã màu và bảng mã code chữ số theo từng chủ đề, đề mục. Code màu các câu trả lời theo các đề mục và biến số. 
Ghép các câu trả lời đã được code màu vào bảng tổng hợp theo chủ đề, đề mục. Những ý kiến sâu sắc và mạnh mẽ của các bạn sinh viên đã được chọn lọc, trích dẫn in nghiêng, giữa hai dấu ngoặc kép và được trình bày trong các hộp.

\section{4. Đạo đức nghiên cứu}

Nghiên cứu đã được thông qua về mặt khoa học và khía cạnh đạo đức trong nghiên cứu tại Trường đại học $Y$ khoa Phạm Ngọc Thạch ngày 04/04/2019, số 1205b/GXN - TĐHYKPNT.

\section{KẾT QUẢ}

\section{Tình trạng trầm cảm}

Hầu hết các bạn sinh viên tham gia nghiên cứu đều cho rằng, tỷ lệ trầm cảm trong sinh viên y đa khoa ngày càng tăng, đặc biệt vào thời gian thi cử.

“...tình trạng thì mình nghĩ nó đang tăng...” Bạn sinh viên ID 132213 - sinh viên Y6.

"...em thấy là hình như gần tới gần mùa thi thì cái hiện tượng đó nó nổi lên nhiều hơn...” Bạn sinh viên ID 163610 - sinh viên Y3.

"...xu hướng trầm cảm của sinh viên trường mình là tăng lên..." - Bạn sinh viên ID 172381 - sinh viên Y2.

\section{Các yếu tố sinh học}

Đa số các sinh viên tham gia phỏng vấn đều cho rằng những sinh viên nhỏ tuổi hơn sẽ dễ mắc trầm cảm hơn so với sinh viên lớp trên.

“...sinh viên ở lớp càng thấp thì càng dễ trầm cảm hơn vì mình đang học Y6 và không hề cảm thấy mệt mỏi như là những năm trước. Có thể bản thân mình đã quen với nhịp học tập, đi lâm sàng và sinh hoạt khi học y..." - Bạn sinh viên ID 132213 - sinh viên Y6.

Các bạn sinh viên tham gia nghiên cứu cũng cho rằng nữ giới có nguy cơ mắc trầm cảm cao hơn nam giới.

“...nũ sẽ dễ bị trầm cảm hơn..." - Bạn sinh viên ID 132213 - sinh viên Y6

\section{Hành vi, lối sống:}

Thói quen ăn uống cũng là một yếu tố mà các bạn sinh viên cho rằng có ảnh hưởng đến trầm cảm, đặc biệt là sinh viên y thường xuyên bỏ bữa do học bài, đi trực và thói quen sử dụng cà phê nhiều.

“...nếu như mà ăn uống không điều độ thì nó cũng sẽ ảnh hưởng...nhưng mà cái việc quan trọng nhất là sinh viên y hình như là uống cà phê hơi nhiều, nhậu nhẹt cũng hơi nhiều!..." Bạn sinh viên ID 132213 - sinh viên Y6.

“...có những ngày em hay cắm học bài, cắm ở cà phê thì uống 1 ly cà phê từ sáng tới chiều Iuôn. Tại vì đi ra đi mua đồ ăn cũng khó. Mấy ngày thi cử là ăn uống từa lưa hết..." - Bạn sinh viên ID 163610 - sinh viên Y3.

Bên cạnh thói quen ăn uống, thói quen ngủ cũng là một yếu tố ảnh hưởng đến trầm cảm của sinh viên y khoa, khi các bạn thường xuyên đi trực đêm, thức khuya học bài.

"...Giấc ngủ thì theo mình nó khá là quan trọng! Tại vì bản thân cũng đang bị mất ngủ... thì cảm giác là cái chuyện đó là cho cái việc học...nó làm cho mình mệt mỏi ảnh hưởng đến việc học...nó cũng là một yếu tố dẫn đến trầm cảm!..." - Bạn sinh viên ID 132213 - sinh viên Y6.

“...ngủ không đủ giấc thì nó cứ cảm giác bực bội, không có muốn đi ra ngoài rồi cả ngày hôm đó em cứ ở lì trong nhà..." - Bạn sinh viên ID 172381 - sinh viên Y2.

\section{Mạng lưới cộng đồng xã hội}

Mối quan hệ với gia đình là một trong những yếu tố tác động nhiều đến tình trạng trầm cảm của sinh viên y khoa, khi gia đình vốn là nơi chia sẻ tâm sự, áp lực của các bạn trong cuộc sống, học tập, thì việc khó chia sẻ hoặc gặp những mâu thuẫn với ba mẹ càng khiến tinh thần của các bạn sinh viên cảm thấy nặng nề hơn.

“...ba mẹ đôi khi không hiểu suy nghĩ của mình, mong muốn mình làm theo ý của họ, 
không tìm được tiếng nói chung, điều đó khiến cho mình cảm thấy áp lực rất nhiều và không muốn chia sẻ gì với ba mẹ..." - Bạn sinh viên ID 132213 - sinh viên Y6.

“...mỗi lần mà mẹ gọi điện thoại cứ hỏi là...có thi được không, chứ không có hỏi là học sao? vui không? hay gì hết...nên nhiều lúc em cũng thấy áp lực lắm..." - Bạn sinh viên ID 172381 sinh viên Y2.

“...mỗi ngày mình gặp ba bác sĩ trong nhà là thôi cứ...con phải là bác sĩ, phải ráng học, phải ráng cho học được cái bằng Khá vô Chợ Rẫy thôi..." - Bạn sinh viên ID 153411 - Sinh viên Y4

Mối quan hệ với bạn bè cũng là một yếu tố có liên quan đến trầm cảm ở sinh viên y khoa. Đặc biệt, theo các bạn sinh viên, tình trạng bị tách biệt, cô lập trong tổ của sinh viên dễ khiến các bạn lạc lõng.

“...ngoài cái chuyện sống chung với ai thì cái chuyện mối quan hệ xung quanh đặc biệt là bạn bè tại vì nó rất là gần, nó gần với mình, ảnh hưởng rất nhiều, giống như là việc học tập hay đi lâm sàng, nếu như mà bạn bè không thấu hiểu hay là không có sự giúp đỡ lẫn nhau thì nó sẽ làm cho người ta có cảm giác rất là bực bội và căng thẳng!..." - Bạn sinh viên ID 132213 sinh viên Y6.

“...Ví dụ như tính xã hội! Tức là mình dùng từ liên kết bầy đàn thôi. Tức là nếu mình không có một cái nhóm mà mình bị tách, bị cô lập á!...” - Bạn sinh viên ID 153411 - Sinh viên Y4.

“...trong cái tổ thì 1 đứa bạn thân trong tổ thì em không nói, còn các bạn khác thì cái cách làm việc với cách suy nghĩ với cái hướng mà họ đề ra cho cái mục tiêu học tập không có giống em..." - Bạn sinh viên ID 163610 - sinh viên Y3.

Theo các bạn sinh viên, việc gặp trở ngại khi tham gia các hoạt động xã hội có ảnh hưởng đến trầm cảm và các bạn sinh viên trầm cảm cũng có xu hướng ngại tham gia các hoạt động xã hội. “...năm nhất thì em có đi mùa hè xanh...năm 2 em cũng có tham gia nhiều. Năm nay thì tại đi bệnh viện nhiều quá nên là em bót đi lại rồi... bây giờ là không muốn tham gia nữa..." - Bạn sinh viên ID 163610 - sinh viên Y3.

\section{5. Điều kiện sống và làm việc}

Theo các bạn sinh viên tham gia nghiên cứu, học lực cũng là một yếu tố liên quan đến trầm cảm của sinh viên, khi học lực vừa là động lực và cũng vừa là áp lực cho các bạn.

“...Học lực á, nếu mà mình thi điểm số không tốt thì...cảm thấy rất là hụt hẫng với bản thân, lo lắng về tương lai...” - Bạn sinh viên ID 132213 - sinh viên Y6.

“...giống như là vài lúc học lực là cái động lực để mình học nhưng mà đôi khi nó là một vật cản mình lại, lần nào học cũng thua thì học làm gì nữa..." - Bạn sinh viên ID 153411 - Sinh viên Y4.

Đi kèm với học lực, áp lực từ việc học hàng ngày cũng ảnh hưởng đến trầm cảm của sinh viên y khoa.

“...Nó có ảnh hưởng rất nhiều, nó làm cho mình phải suy nghĩ rất nhiều về cái việc học của mình với cái năng lực của bản thân..." - Bạn sinh viên ID 132213 - sinh viên Y6.

“...Bình thường là mình sẽ ráng, mình sẽ quyết tâm, ừ mình sẽ học ừ mình thua nó xíu chắc cũng không sao chưa chắc là bác sĩ không tốt...nhưng mà khi ra cái bảng điểm cái là bắt đầu cái mood nó xuống từ từ..." - Bạn sinh viên ID 153411 - Sinh viên Y4.

Chương trình học của sinh viên y đa khoa cũng là yếu tố liên quan đến trầm cảm ở sinh viên y khoa.

“...thời gian học nó cũng đã dài hơn nè... làm cho mình buồn khi phải so sánh với nhũ̃ng ngành khác, với phần nữa là cái việc đi học nhiều như vậy thì không có thời gian để chơi với những người bạn trước đó, bạn cấp 3 chẳng hạn...thì việc đó làm cho mình cảm thấy bị bỏ 
rơi..." - Bạn sinh viên ID 132213 - sinh viên Y6.

“...nhưng mà càng lên cao thì cái chương trình học nó càng khó nhưng mà nó kiểu là đí.. đi lâm sàng nhiều hơn nên nếu mà ai thích thì sẽ đỡ trầm cảm hơn, còn mà không thích thì chắc là..." - Bạn sinh viên ID 172381 - sinh viên Y2.

Các yếu tố còn lại như: nơi ở, dân tộc, tôn giáo, thi rớt hoặc nợ môn, mức học phí, chi phí sách vở, dụng cụ học tập theo các bạn sinh viên tham gia nghiên cứu là không có mối liên quan với trầm cảm ở sinh viên.

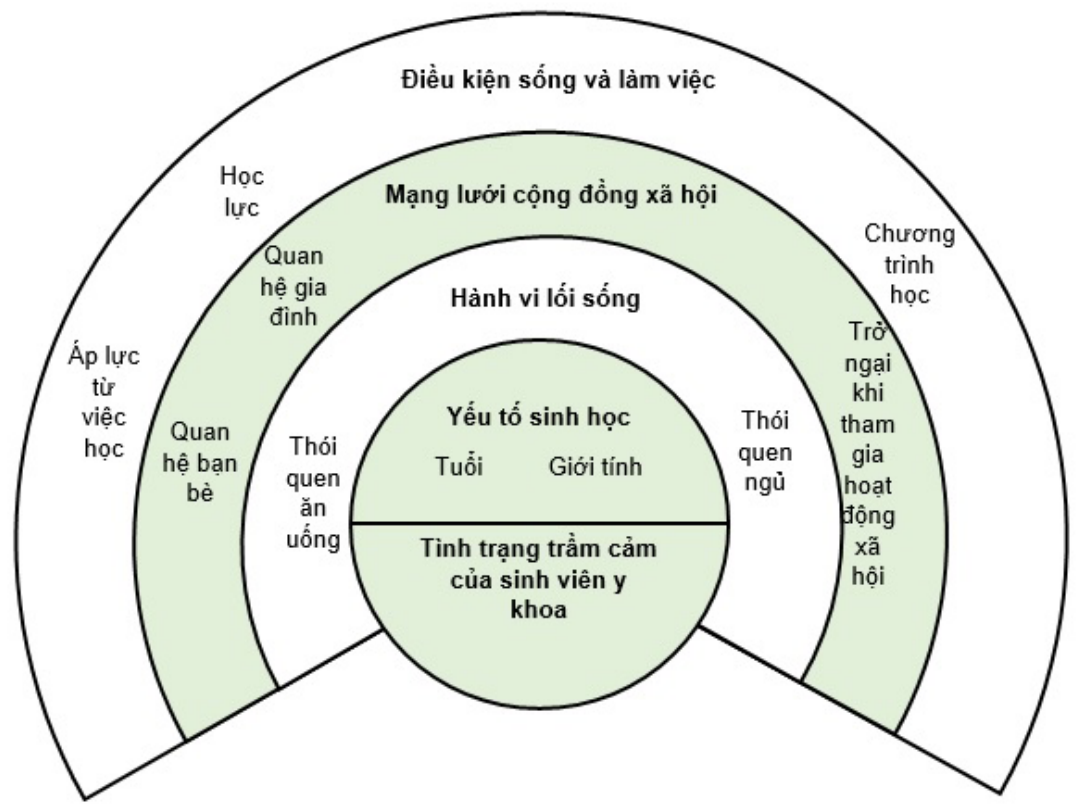

Hình 1. Mô hình các yếu tố liên quan đến tình trạng trầm cảm của sinh viên y khoa dưới góc nhìn của sinh viên y khoa

\section{BÀN LUẬN}

Các sinh viên cho rằng tỷ lệ trầm cảm của sinh viên đang ngày một tăng lên, và ý kiến này khá phù hợp với các nghiên cứu định lượng trước đây, khi hầu hết các nghiên cứu trong và ngoài nước đều cho kết quả tỷ lệ sinh viên mắc trầm cảm rất cao trong suốt các năm học. 5, 8-10

Dù chưa tìm được một nghiên cứu định tính nào ghi nhận góc nhìn sinh viên y khoa về mối liên quan giữa tuổi và giới tính với trầm cảm, tuy nhiên khi so sánh với các nghiên cứu định lượng khác, chúng tôi vẫn thấy có sự tương đồng khi các nghiên cứu định lượng tìm thấy mối liên quan giữa tuổi, giới tính với trầm cảm của sinh viên. ${ }^{5,10-12}$

Kết quả nghiên cứu định tính của Winitra Kaewpila và các cộng sự tại Thái Lan cho thấy rằng sinh viên y khoa thường dành ít nhất 8 giờ mỗi ngày, 5 ngày một tuần, trong những năm liền để đi lâm sàng, điều này đã ảnh hưởng rất lớn đến thói quen ăn uống và thói quen ngủ của các bạn sinh viên. ${ }^{6}$ Nghiên cứu định tính của Monica $\mathrm{R}$. Hill và các cộng sự cho thấy rằng, sinh viên y khoa đang gặp vấn đề trầm trọng trong việc thiếu ngủ và các bạn rất khó khăn để có thể duy trì một lối sống khỏe mạnh, đặc biệt là rất nhiều sinh viên chuyển sang uống rượu 
để thư giãn giống như đề cập của một sinh viên trong nghiên cứu của chúng tôi. ${ }^{13}$ Các nghiên cứu định lượng trước đây cũng cho thấy mối liên quan giữa các yếu tố trên và trầm cảm ở sinh viên y khoa. ${ }^{10,11}$

Cũng theo kết quả nghiên cứu định tính của Winitra Kaewpila và các cộng sự tại Thái Lan, các vấn đề về các mối quan hệ dường như là mối quan tâm lớn của sinh viên y khoa. Khi sinh viên gặp trục trặc trong mối quan hệ với gia đình, bạn bè, người yêu, hoặc khi tham gia hội nhóm có khả năng bắt đầu vào thời kỳ trầm cảm. ${ }^{6}$ Theo kết quả nghiên cứu định tính của Monica R. Hill và các cộng sự việc cạnh tranh giữa các bạn bè trong lớp cũng khiến cho sinh viên cảm thấy áp lực. ${ }^{13}$ Các nghiên cứu định lượng cũng cho kết quả tương tự. 5, 10, 11

Nghiên cứu định tính của Winitra Kaewpila và các cộng sự ở Thái Lan cũng cho kết quả tương tự khi các sinh viên tham gia rất quan tâm đến học lực và luôn cố gắng để đạt được kết quả tốt. Bên cạnh đó sinh viên cũng luôn cảm thấy căng thẳng và áp lực về việc học của mình. Chương trình học với khối lượng kiến thức dồi dào, lịch học dày với những bài kiểm tra liên tục cũng khiến sinh viên dễ rợ vào trầm cảm. ${ }^{6}$ Kết quả nghiên cứu định tính của Monica R. Hill và các cộng sự cũng cho kết quả tương tự khi các sinh viên mắc trầm cảm cho rằng khối lượng kiến thức ngành y quá nhiều và tốc độ của chương trình học khiến các sinh viên cảm thấy chơi vơi để theo kịp, áp lực về thành tích học tập cũng khiến các bạn sinh viên dễ mắc trầm cảm hơn. ${ }^{13}$

\section{KÉT LUẬN}

Sinh viên y khoa đã nhận thức được tỷ lệ trầm cảm của sinh viên y khoa đang ngày một tăng, các yếu tố liên quan mà sinh viên cho rằng có tác động đến tỷ lệ trầm cảm của sinh viên y khoa bao gồm: Tuổi, giới tính, thói quen ăn uống, thói quen ngủ, mối quan hệ với gia đình, mối quan hệ với bạn bè, gặp trở ngại khi tham gia các hoạt động xã hội, học lực, áp lực từ việc học, chương trình học.

\section{Kiến nghị}

Sinh viên cũng nên tham gia các hoạt động xã hội, các Câu lạc bộ - Đội - Nhóm sau giờ học và thường xuyên trò chuyện, chia sẻ với bạn bè và gia đình nhằm giải tỏa áp lực, căng thẳng trong quá trình học tập và thi cử. Bên cạnh đó, sinh viên nên tìm hiểu cách kiểm soát và giải tỏa cảm xúc của bản thân, tránh dồn nén cảm xúc gây căng thẳng và tự tạo áp lực cho bản thân. Các bậc phụ huynh nên hạn chế tạo áp lực, thường xuyên chia sẻ, tạo tâm lý thoải mái và niềm đam mê học tập cho con của mình. Nhà trường cần nên phân bổ lại chương trình học các năm hợp lý để tránh dồn dập nhiều môn học trong một năm học.

\section{TÀI LIẸU THAM KHẢO}

1. World Health Organization. Depression: let's talk. 2017; at the website https://www.who. int/mental_health/management/depression/ en/. Accessed accessed on 2 Dec 2018.

2. World Health Organization. Depression. 2018; at the website https://www.who.int/news room/fact - sheets/detail/depression. Accessed accessed on 2 Dec 2018.

3. World Health Organization. "Depression: let's talk" says WHO, as depression tops list of causes of ill health. 2017; at the website https:// www.who.int/news - room/detail/30 - 03 - 2017 - - depression - let - s - talk - says - who - as - depression - tops - list - of - causes - of - ill health. Accessed accessed on 2 Dec 2018.

4. Storrie K., Ahern K., tuckett A. A systematic review: Students with mental health problems - - a growing problem. International journal of nursing practice. Feb 2010; volume 16(1):pp. 1 -6 .

5. Anh T.Q, Dunne Michael P., Hoat L.N. Well - being, depression and suicidal ideation 
among medical students throughout vietnam Vietnam Journal Of Medicine \& Pharmacy 2014; volume 6(3):pp.23 - 30.

6. Kaewpila W, thaipisuttikul P, Awirutworakul $\mathrm{T}$, Jumroonrojana K, Pitidhammabhorn $\mathrm{U}$, Stevens F. Depressive disorders in Thai medical students: an exploratory study of institutional, cultural, and individual factors. International journal of medical education. 2020;11:252 - 260.

7. Dahlgren G, Whitehead M. Policies and Strategies to Promote Social Equity in Health. Stockholm, Sweden: Institute for Futures Studies. 1991.

8. Puthran R., Zhang M. W., tam W. W., Ho R. C. Prevalence of depression amongst medical students: a meta - analysis. Medical education. Apr 2016; volume 50(4):pp.56 - 68.

9. Fawzy M., Hamed S. A. Prevalence of psychological stress, depression and anxiety among medical students in Egypt. Psychiatry research. Sep 2017; volume 255:pp.186 - 194.

10. Nguyễn Hoàng Việt Đức. Dấu hiệu trầm cảm và một số yếu tố liên quan ở một số khối sinh viên đa khoa Trường Đại học $Y$ dược Hải Phòng năm 2015. Khóa luận tốt nghiệp Bác sĩ y học dự phòng, Đại học $Y$ dược Hải Phòng; 2015.

11. Hồng Tha. Tỉ lệ trầm cảm của sinh viên ký túc xá Đại học $Y$ Dược Thành phố Hồ Chí Minh và một số yếu tố liên quan. Khóa luận tốt nghiệp Bác sĩ y học dự phòng, Khoa Y Tế Công Cộng, Đại học Y Dược Thành phố Hồ Chí Minh; 2016.

12. Mahroon Z. A., borgan S. M., Kamel C., Maddison W., Royston M., Donnellan C. Factors Associated with Depression and Anxiety Symptoms Among Medical Students in Bahrain. Academic psychiatry : the journal of the American Association of Directors of Psychiatric Residency Training and the Association for Academic Psychiatry. Feb 2018;volume 42(1):pp.31 - 40.

13. Hill MR, Goicochea S, Merlo LJ. In their own words: stressors facing medical students in the millennial generation. Med Educ Online. 2018;23(1):1530558 - 1530558.

\section{Summary \\ MODEL OF PREDICTING THE LEVEL OF SELF-MANAGEMENT MEDICAL STUDENTS' DEPRESSION: MEDICAL STUDENTS' VIEWS THROUGH A QUALITATIVE STUDY}

Depression is becoming a public health concern as the proportion of people suffering from depression of all ages is increasing rapidly. This study aims to describe medical students' views about depression and association factors of medical students at the Pham Ngoc Thach University of Medicine in 2019, with the participation of 4 students. The results show that medical students are aware that the prevalence of depression among medical students is increasing; associated factors included age, gender, eating habits, sleeping habits, relationship with family, relationship with friends, barriers towards social activities, academic performance and study load pressure.

Keywords: Depression, association factors, medical students, qualitative research 